\title{
Assessment of Spectroscopic, Real-Time Ion Thruster Grid Erosion-Rate Measurements
}

Matthew T. Domonkos

Glenn Research Center, Cleveland, Ohio

Richard E. Stevens

Whitworth College, Spokane, Washington 
Since its founding, NASA has been dedicated to the advancement of aeronautics and space science. The NASA Scientific and Technical Information (STI) Program Office plays a key part in helping NASA maintain this important role.

The NASA STI Program Office is operated by Langley Research Center, the Lead Center for NASA's scientific and technical information. The NASA STI Program Office provides access to the NASA STI Database, the largest collection of aeronautical and space science STI in the world. The Program Office is also NASA's institutional mechanism for disseminating the results of its research and development activities. These results are published by NASA in the NASA STI Report Series, which includes the following report types:

- TECHNICAL PUBLICATION. Reports of completed research or a major significant phase of research that present the results of NASA programs and include extensive data or theoretical analysis. Includes compilations of significant scientific and technical data and information deemed to be of continuing reference value. NASA's counterpart of peerreviewed formal professional papers but has less stringent limitations on manuscript length and extent of graphic presentations.

- TECHNICAL MEMORANDUM. Scientific and technical findings that are preliminary or of specialized interest, e.g., quick release reports, working papers, and bibliographies that contain minimal annotation. Does not contain extensive analysis.

- CONTRACTOR REPORT. Scientific and technical findings by NASA-sponsored contractors and grantees.
- CONFERENCE PUBLICATION. Collected papers from scientific and technical conferences, symposia, seminars, or other meetings sponsored or cosponsored by NASA.

- SPECIAL PUBLICATION. Scientific, technical, or historical information from NASA programs, projects, and missions, often concerned with subjects having substantial public interest.

- TECHNICAL TRANSLATION. Englishlanguage translations of foreign scientific and technical material pertinent to NASA's mission.

Specialized services that complement the STI Program Office's diverse offerings include creating custom thesauri, building customized data bases, organizing and publishing research results ... even providing videos.

For more information about the NASA STI Program Office, see the following:

- Access the NASA STI Program Home Page at $h t t p: / / w w w . s t i . n a s a . g o v$

- E-mail your question via the Internet to help@sti.nasa.gov

- Fax your question to the NASA Access Help Desk at (301) 621-0134

- Telephone the NASA Access Help Desk at (301) 621-0390

- Write to:

NASA Access Help Desk

NASA Center for AeroSpace Information 7121 Standard Drive Hanover, MD 21076 


\section{Assessment of Spectroscopic, Real-Time Ion Thruster Grid Erosion-Rate Measurements}

Matthew T. Domonkos

Glenn Research Center, Cleveland, Ohio

Richard E. Stevens

Whitworth College, Spokane, Washington

Prepared for the 36th Joint Propulsion Conference and Exhibit cosponsored by the AIAA, ASME, SAE, ASEE Huntsville, Alabama, July 16-19, 2000

National Aeronautics and

Space Administration

Glenn Research Center 
Available from

NASA Center for Aerospace Information 7121 Standard Drive

Hanover, MD 21076

Price Code: A03
National Technical Information Service 5285 Port Royal Road Springfield, VA 22100 Price Code: A03

Available electronically at http:/ / gltrs.grc.nasa.gov/GLTRS 


\title{
ASSESSMENT OF SPECTROSCOPIC, REAL-TIME ION THRUSTER GRID EROSION-RATE MEASUREMENTS MATTHEW T. DOMONKOS
}

\author{
National Aeronautics and Space Administration \\ Glenn Research Center \\ Cleveland, Oh 44135 \\ Richard E. Stevens \\ Whitworth College \\ Spokane, WA 99251
}

\begin{abstract}
The success of the ion thruster on the Deep Space One mission has opened the gate to the use of primary ion propulsion. Many of the projected planetary missions require throughput and specific impulse beyond those qualified to date. Spectroscopic, real-time ion thruster grid erosion-rate measurements are currently in development at the NASA Glenn Research Center. A preliminary investigation of the emission spectra from an NSTAR derivative thruster with titanium grid was conducted. Some titanium lines were observed in the discharge chamber; however, the signals were too weak to estimate the erosion of the screen grid. Nevertheless, this technique appears to be the only non-intrusive real-time means to evaluate screen grid erosion, and improvement of the collection optics is proposed. Direct examination of the erosion species using laser-induced fluorescence (LIF) was determined to be the best method for a real-time accelerator grid erosion diagnostic. An approach for a quantitative LIF diagnostic was presented.
\end{abstract}

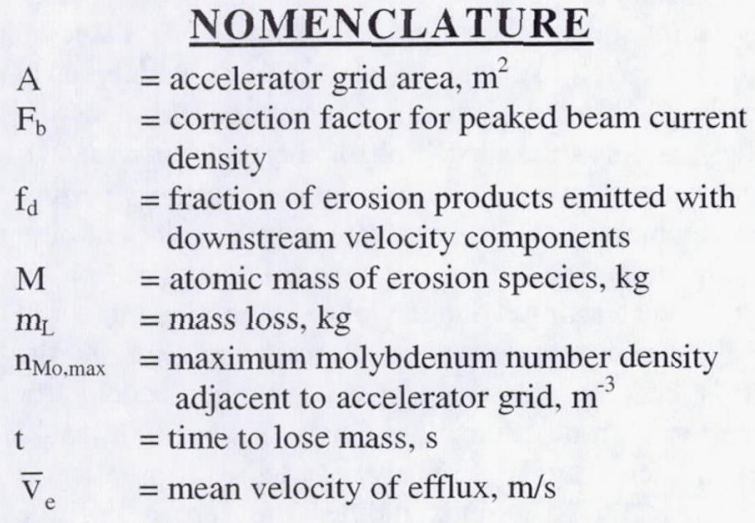

\section{INTRODUCTION}

The dramatic success of the NASA Solar Electric Propulsion Test Applications and Readiness (NSTAR) $30-\mathrm{cm}$ ion thruster on Deep Space One has proven that the technological barriers to the use of primary electric propulsion have been overcome. ${ }^{1,2,3}$ The NSTAR ion thruster demonstrated life to 8192 hours with a xenon throughput of $88-\mathrm{kg}$ in a ground test, and the ongoing extended life-test (ELT) has logged over 11,000-hours and $96-\mathrm{kg}$ of xenon to date. 1,2 Despite these triumphs, the user community requires still more throughput and at higher thrust and specific impulse than that demonstrated by the NSTAR ion engine. ${ }^{4}$ In addition to the Comet
Nucleus Sample Return (CNSR) mission which plans to use four NSTAR derivative thrusters, NASA Glenn Research Center (GRC) is also actively developing a 5-kW ion thruster, a $30-\mathrm{kW}$ Interstellar Precursor ion thruster, a 100-300-W ion thruster, and a hollow cathode micro-ion thruster. ${ }^{5,6}$ To reduce the real and perceived risks associated with new propulsion systems, ground based life-tests will continue to be conducted for the foreseeable future. With the cost of qualifying thrusters for spaceflight measured in millions of dollars and multiple years, accurate and timely evaluation of thruster performance and predicted life is critical to the deployment of advanced ion thruster systems. This paper presents the ongoing work being conducted at NASA Glenn Research Center to assess and to develop real-time, spatially resolved erosion diagnostics in support of advanced ion thruster research.

The discharge cathode and both the accelerator and screen grids in ion thrusters have exhibited sputter erosion. ${ }^{1}$ In the NSTAR configuration, the accelerator grid appears to be the primary lifelimiting component, although anomalous erosion in the vicinity of the cathode tip has been observed in a 2000-hour test conducted at GRC ${ }^{1,7}$ and the ongoing ELT. The anomalous cathode erosion is the subject of another study, ${ }^{8}$ and the present work focuses on 
grid erosion. Sputtering from discharge chamber ion impingement is the primary mechanism for erosion of the screen grid. In principle, screen grid erosion is a function of the ion current and energy, both of which can be measured accurately. In practice, the prediction of screen grid life is complicated by the relatively poor understanding of the sputter yield near threshold voltages and the possible presence of high energy ions emitted from the discharge cathode.' Accelerator grid erosion also occurs via ion bombardment. Kerslake ${ }^{10}$ first presented the theory of charge exchange ion production being responsible for accelerator grid wear. As the beam ions flow downstream, some of them undergo resonant chargeexchange collisions with propellant or background atoms. The newly formed fast neutral atom continues its downstream trajectory largely unaffected by the collision, while the resulting slow ion, born deep in a potential well, undergoes electrostatic acceleration toward the negatively biased accelerator grid. The charge-exchange ion then collides with the accelerator grid, sputtering grid material according to the sputter yield. The most probable locations for the formation of charge exchange collisions result in sputter erosion which enlarges the grid apertures and also creates the familiar "pits and grooves" erosion pattern on the downstream surface. ${ }^{2,11}$ Accelerator grid lifetime may be defined either by the point where electron backstreaming can no longer be prevented by the existing power supplies due to aperture enlargement, or by structural failure due to the "pits and grooves" material loss. The former mechanism is believed to dominate grid erosion in space where neutrals for charge exchange collisions come only from the thruster, and not the facility gas.

This paper describes the initiation of an effort to develop real-time, spatially-resolved grid erosion diagnostics at the NASA Glenn Research Center. A background into erosion-rate diagnostics is presented. Next, a preliminary experimental investigation is summarized. Initially, emission spectra were collected and analyzed to evaluate the thruster environment and to assess which techniques are appropriate for the screen and accelerator grids, respectively. In addition, the screen grid was biased to enhance its erosion, and thereby strengthen the emission spectra. The results of the emission spectroscopic measurements are discussed. Finally, a proposed experimental architecture for an accelerator grid lifetime measurement based on a LIF density diagnostic is presented.

\section{BACKGROUND}

Erosion measurements can be categorized by the following: the number of hours of operation required to measure the erosion, whether it is sensitive to the type of erosion, the level of component handling, the spatial resolution, and the ability to predict grid lifetime from the data. Many erosion measurement techniques only provide useful results after the grids have been operated for several hundred hours. Ideally, the erosion measurement can differentiate aperture enlargement from the "pits and grooves" wear. Relatively few erosion diagnostics are conducted in situ, without dismantling the thruster. The typically peaked profile of the ion current density leads to a radial variation in erosion, and the spatial resolution capacity of the erosion diagnostics vary. The peak ion current density determines the point of failure in the accelerator grid, although the distribution of sputtered efflux is of interest for spacecraft designers in assessing integration. The ability to predict grid life varies with the diagnostic, and direct measurements of grid shape or operating characteristics are typically the most accurate measurements by this criterion. Ion thruster grid erosion measurements are discussed relative to these figures of merit in this section.

Many techniques have been implemented to measure ion thruster grid erosion, and Table 1 summarizes the attributes of the most widely used methods. Observation of the perveance limit or the electron backstreaming limit of the grids provides an indirect measure of accelerator grid aperture enlargement. As the apertures enlarge, ion impingement on the accelerator grid occurs at smaller total accelerating voltage values, and the threshold bias to prevent electron backstreaming through the grids becomes more negative. As the accelerator apertures erode, mass loss analysis of grid erosion has been used extensively to estimate grid lifetime. $^{12,13,14,15}$ Since neither the screen nor the accelerator grid erode uniformly, mass loss analysis must be used in conjunction with another method or modeling to determine grid life. Destructive analysis has been performed to examine the topographical nature of grid erosion. ${ }^{2,12}$ While destructive analysis enables direct examination of the erosion profile, the technique is impractical for acceptance testing or time-resolved measurement. Beattie and Poeschel pioneered the use of erosion witness badges which employ alternative thin layers of different color 
Table 1 - Assessment of Erosion Measurement Techniques.

\begin{tabular}{|c|c|c|c|c|c|c|}
\hline Technique & $\begin{array}{l}\text { Parameter } \\
\text { Measured }\end{array}$ & $\begin{array}{c}\begin{array}{c}\text { Time } \\
\text { (hours) }\end{array}\end{array}$ & $\begin{array}{c}\text { Mechanism } \\
\text { Differentiation }\end{array}$ & $\begin{array}{c}\text { Grid } \\
\text { Handling }\end{array}$ & $\begin{array}{c}\text { Spatial } \\
\text { Resolution }\end{array}$ & $\begin{array}{c}\text { Ability to } \\
\text { Predict Life }\end{array}$ \\
\hline $\begin{array}{l}\text { Perveance } \\
\text { Limit }\end{array}$ & $\begin{array}{l}\text { Accelerator } \\
\text { Grid Current }\end{array}$ & 100 's & $\begin{array}{l}\text { No. Only for } \\
\text { aperture } \\
\text { diameter. }\end{array}$ & None & None & Good \\
\hline $\begin{array}{c}\text { Electron } \\
\text { Backstreaming }\end{array}$ & $\begin{array}{l}\text { Beam } \\
\text { Current }\end{array}$ & 100 's & $\begin{array}{l}\text { No. Only for } \\
\text { aperture } \\
\text { diameter. }\end{array}$ & None & None & Good \\
\hline Mass Loss & Mass & 100 's & No & $\begin{array}{l}\text { Removal from } \\
\text { Thruster }\end{array}$ & None & Poor \\
\hline Destructive & $\begin{array}{l}\text { Profile and } \\
\text { Aperture } \\
\text { Diameter }\end{array}$ & 100 's & Yes & $\begin{array}{l}\text { Removal from } \\
\text { Thruster and } \\
\text { Destruction }\end{array}$ & Yes & $\begin{array}{l}\text { Good (single } \\
\text { data point only) }\end{array}$ \\
\hline Witness Badges & Profile & 100 's & $\begin{array}{l}\text { No. Only for } \\
\text { "Pits and } \\
\text { Grooves" }\end{array}$ & $\begin{array}{l}\text { Removal from } \\
\text { Thruster }\end{array}$ & Yes & Poor \\
\hline $\begin{array}{l}\text { Accelerated } \\
\text { Wear Tests }\end{array}$ & $\begin{array}{c}\text { Mass and/or } \\
\text { Profile }\end{array}$ & 100 's & $\begin{array}{c}\text { Perturbs In-Space } \\
\text { Mechanism }\end{array}$ & $\begin{array}{c}\text { Removal from } \\
\text { Thruster }\end{array}$ & Yes & Poor \\
\hline $\begin{array}{l}\text { QCM / } \\
\text { Deposition } \\
\text { Slides }\end{array}$ & $\begin{array}{c}\text { Sputter } \\
\text { Material } \\
\text { Deposition }\end{array}$ & 100 's & No & None & None & Poor \\
\hline Profilometry & $\begin{array}{l}\text { Profile and } \\
\text { Aperture } \\
\text { Diameter }\end{array}$ & 100 's & Yes & None if in situ & Yes & Excellent \\
\hline Microscopy & $\begin{array}{l}\text { Profile and } \\
\text { Aperture } \\
\text { Diameter }\end{array}$ & 100 's & Yes & $\begin{array}{c}\text { Removal from } \\
\text { Thruster }\end{array}$ & Yes & Excellent \\
\hline $\begin{array}{c}\text { Emission } \\
\text { Spectroscopy }\end{array}$ & Density & $\sim 1$ & Possible & None & Yes & $\begin{array}{c}\text { Good (Screen } \\
\text { Grid } \\
\text { Demonstrated) }\end{array}$ \\
\hline LIF Density & Density & $\sim 1$ & Yes & None & Yes & $\begin{array}{l}\text { Good (Accel } \\
\text { Grid) }\end{array}$ \\
\hline
\end{tabular}

metals to indicate relative wear rates. ${ }^{16,17}$ The witness badges consisted of alternating thin layers of the target material (molybdenum) and a different colored metal (copper) which also erodes much more quickly than the target metal. The badges were spot welded to the grid surface. After several tens of hours of operation, the witness badges were examined, and the amount of erosion was measured by counting the number of layers that had been removed in an area. This diagnostic was limited by the thickness of the deposited layers, and whether the deposited molybdenum in the badge had the same sputter yield as the bulk material in the grids was left undetermined. An accelerated wear-test was conducted by Brophy, Polk, and Pless ${ }^{14}$ in order to highlight the erosion of two-grid optics, however the elevated facility pressure used to hasten the wear altered the dominant erosion mechanism. With elevated background pressure, charge exchange collisions occur further downstream of the thruster, and as the charge-exchange ions are born farther from the thruster, they are more likely to be focused onto the web and beyond the active area of the grid. Accelerated wear-tests constitute an erosion measurement technique only when combined with one or more of the methods described here. Several investigations have used the arrival rate of erosion products at a quartz crystal microbalance or deposition slides to estimate a bulk erosion-rate. ${ }^{18,19}$ Material deposition is an indirect erosion measurement, and the ability to predict grid lifetime is consequently limited. The source of the material cannot be determined precisely, and typically the material composition must be determined independently. Profilometry and microscopy have been used to examine erosion topography in a nondestructive manner. ${ }^{2,13,15,20,21,22}$ The principle for both profilometry and microscopy is to determine the erosion profile based on the focal point of an optical system. The use of a laser range sensor enables 
profilometry to be conducted in situ, while microscopy is performed manually after the grids have been removed from the thruster. Both techniques provide a great deal of spatial resolution and can be used to determine aperture enlargement.

While each of the previously mentioned methods to determine grid erosion and life has advantages, they all share the same disadvantage: the thruster must be operated for at least several hundreds of hours before an accurate erosion-rate can be inferred. Use of an in-situ profilometer during the 8192-hour NSTAR wear-test showed that the "pit and groove" erosion-rates were independent of the operational hours accrued. ${ }^{2}$ This fact means that a real-time erosion-rate measurement will yield a representative "pit and groove" wear-rate, and the grid lifetime may be calculated from these data. ${ }^{2}$ Examination of the perveance limit and electron backstreaming limit data from the 8192-hour weartest implies that the beginning-of-life aperture enlargement rate was slightly higher than that after approximately 2000-hours. ${ }^{2}$ Since perveance and electron backstreaming limits are indirect measures of grid aperture erosion, additional work must be performed to establish whether the aperture enlargement rate is constant over time. Under conditions where erosion-rates are expected to be constant over time, real-time erosion rate measurements mitigate the need for extended duration testing to determine wear-rates and are limited only by the minimum level of detectable erosion. Background information on three real-time erosion-rate diagnostics is discussed below.

Optical emission spectroscopy was proposed by Rock, Mantenieks, and Parsons ${ }^{23}$ as a means to measure ion thruster screen grid erosion in real-time. Although ion thruster discharge chamber plasmas typically fail to meet the conditions for local thermodynamic equilibrium, a kinetic steady state model was used in which a set of rate equations describing the population of excited states was solved, yielding relative densities. By examining the relative intensities of a set of neutral molybdenum spectral lines and utilizing an empirically derived description of the discharge plasma, the density was calculated consistently with the sputter yield from the screen grid. This technique is dependent upon accurate determination of the discharge chamber plasma environment and ample line intensity in the erosion product species. Nevertheless, Rock, Mantenieks, and Parsons ${ }^{23}$ were able to predict screen grid erosion-rates to within twenty percent.

Laser spectroscopic techniques have also been used to determine neutral and ionic densities. While laser absorption is an established method for determining particle density, the path-length necessary for accurate determination of the density of erosion products complicates its implementation. Laser-induced fluorescence (LIF) has also been employed as a real-time, spatially-resolved erosionrate diagnostic. ${ }^{24,25,26}$ Each of these studies yielded results on the relative erosion product density for accelerator grid biases between -200 and $-500-\mathrm{V}$. This operating range accentuated the grid erosion for the benefit of the diagnostic. Others have successfully implemented quantitative LIF in other systems with molybdenum ${ }^{27}$ and with titanium, ${ }^{28}$ both of which are candidate grid materials. LIF holds promise for determining the absolute accelerator grid erosion-rate for realistic operating conditions, and the remainder of this paper describes a preliminary emission spectroscopic investigation and analysis to further assess the applicability of laser and emission based optical diagnostics to measure ion thruster grid erosion-rates.

\section{EXPERIMENTAL APPARATUS}

Emission spectra from the GRC test-bed ion thruster, a NSTAR derivative, were collected at a number of operating conditions. The goal of the spectroscopic investigation was to examine the emission characteristics of an ion thruster over a wide range of operating conditions. The results will be used to determine which transitions to target for future investigations.

\section{GRC Test-Bed Ion Thruster}

Geometrically, the GRC test-bed ion thruster, shown in Figure 1, is nearly identical to the NSTAR thruster. The significant differences from the NSTAR configuration are the use of an aluminum discharge chamber and titanium optics for these tests. The power processing unit was modified to allow operation to $5-\mathrm{kW}$, and Table 2 represents the ideal throttle table for the engine. During this investigation, the thruster was operated at throttling levels $28,19,15,12,10,8,4$, and 0 . The maximum beam voltage and current were $1500-\mathrm{V}$ and $2.70-\mathrm{A}$, respectively. For further details concerning the thruster, the reader is referred to Patterson et al. ${ }^{5}$

\section{Propellant Feed System}

High purity xenon was supplied to the thruster using an inert gas feed system, designed for performance assessments of $30-\mathrm{cm}$ thrusters. The feed system has an in-situ propellant flow-rate calibration capability which agrees with a National Institute of Standards and Technology (NIST) traceable bubble flow-meter to within four percent. Propellant flow rates were controlled to within 0.1sccm for the discharge, discharge cathode, and 
neutralizer. The quality of the feed system ensured that only trace amounts of contaminant gases, which would complicate spectral identification, reached the discharge.

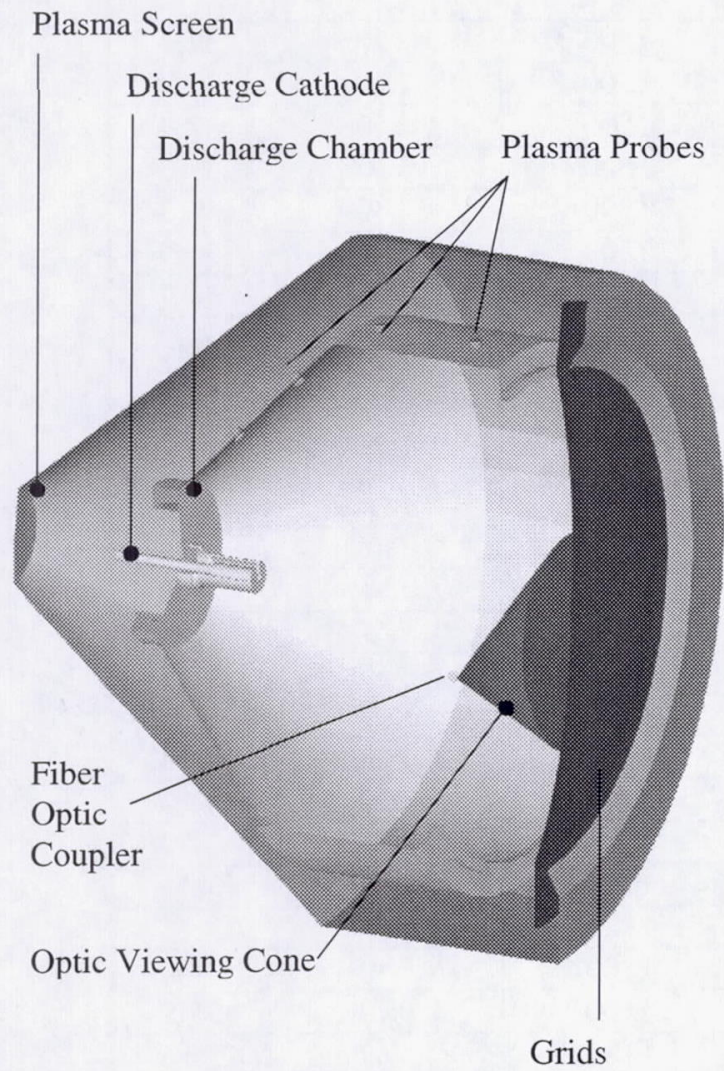

Figure 1 - Schematic of the test-bed Ion Thruster with the Internal Fiber Optic Probe.

\section{Vacuum Facility}

The tests were conducted in Vacuum Facility 11 (VF-11) at GRC, shown in Figure 2, which is $2.2-\mathrm{m}$ in diameter by $7.9-\mathrm{m}$ long. The chamber is made of aluminum, and the interior is lined with stainless steel sheets. The facility was held between 1.9 and $7.5 \times 10^{-4}-\mathrm{Pa}$ during these tests by $40.9-\mathrm{m}$ diameter and 3 1.2-m diameter gaseous helium cryopumps which provided a pumping speed of approximately $110,000 \mathrm{~L} / \mathrm{s}$ on xenon. Noncondensable gases, such as helium, were removed from the chamber by a turbo-molecular pump.

\section{Optical Diagnostics}

Fiber optics with a core diameter of $200-\mu \mathrm{m}$ and approximately $25-\mathrm{m}$ long were used to deliver the emissions from the thruster to a $0.5-\mathrm{m}$ spectrometer equipped with a fiber optic coupler. A fiber optic probe was mounted flush with the wall of the discharge chamber as shown in Figure 1. Spectra were also collected in a $50-\mathrm{mm}$ by $6-\mathrm{mm}$ slab perpendicular to the thruster axis, immediately downstream of the grids, however, these emissions proved too weak to be collected using fiber optics. The spectrometer entrance slit dimensions were set to $1-\mathrm{mm}$ wide by $2-\mathrm{mm}$ high to accommodate the relatively weak signal from the fiber optics. A $2400-$ lines/mm holographic grating optimized for ultraviolet wavelengths was used to enhance the transmission of the erosion product spectra, much of which lies between 300 and 400-nm. A photomultiplier tube with detection capability over the range from 180 to $900-\mathrm{nm}$ was used to measure the signal. The spectra were collected with a computer data acquisition system, and scans were typically conducted going from 350 to $650-\mathrm{nm}$ in 0.5 -nm increments with a 0.3 -s integration time. The system linearity and resolution were calibrated using a mercury Plucker tube. Using a tungsten filament lamp, magnitude calibrations were conducted before and after testing to correct for any deposition of eroded material on the fiber. The calibrations showed the deposition to be negligible, and the system, including the fiber optic, was sensitive well into the ultraviolet as illustrated in Figure 3.

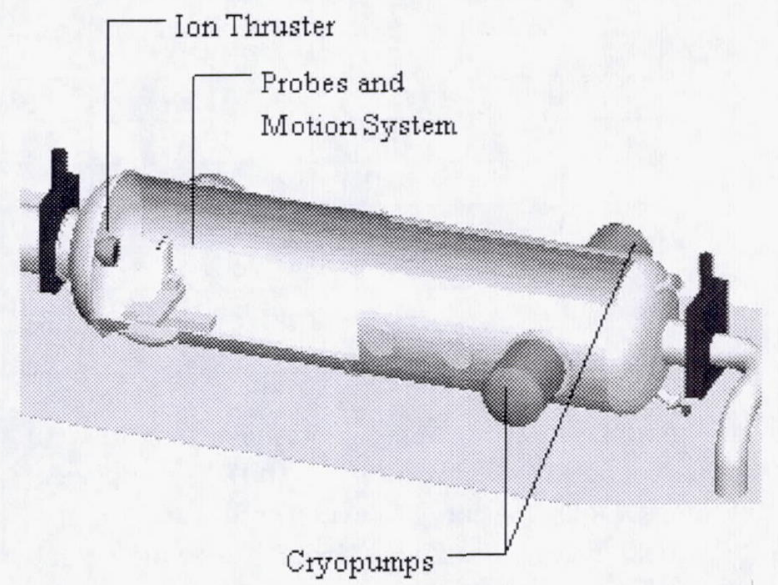

Figure 2 - Vacuum Facility 11 at GRC.

The uncorrected spectra, collected at throttle level 28, is depicted in Figure 4. The majority of the peaks represent neutral and singly-ionized Xe. The spectra in the near-UV is enlarged to illustrate that some structure was observed in the emission at these wavelengths. In cases where the resolution prevented a clear distinction between xenon and titanium, the line was assumed to be xenon due to its relative abundance in the discharge chamber. Emission wavelengths, Einstein coefficients, and degeneracies 
Table 2 - Ideal Throttling Table for the Test-Bed Ion Thruster.

\begin{tabular}{|c|c|c|c|c|c|c|}
\hline $\begin{array}{c}\text { Throttle } \\
\text { Level }(\mathbf{T H})\end{array}$ & $\begin{array}{c}\text { Thrust } \\
(\mathbf{m N})\end{array}$ & $\begin{array}{c}\text { Thruster Input } \\
\text { Power }(\mathbf{W})\end{array}$ & $\begin{array}{c}\text { Engine } \\
\text { Efficiency }\end{array}$ & $\begin{array}{c}\text { Beam Voltage, } \\
\mathbf{V}_{\mathbf{b}}(\mathbf{V})\end{array}$ & $\begin{array}{c}\text { Beam Current, } \\
\mathbf{J}_{\mathbf{b}}(\mathbf{A})\end{array}$ & $\mathbf{I}_{\mathbf{s p}}(\mathbf{s})$ \\
\hline 28 & 165 & 4595 & 0.698 & 1500 & 2.70 & 3953 \\
\hline 27 & 159 & 4427 & 0.696 & 1500 & 2.60 & 3944 \\
\hline 26 & 153 & 4256 & 0.695 & 1500 & 2.50 & 3934 \\
\hline 25 & 147 & 4088 & 0.693 & 1500 & 2.40 & 3923 \\
\hline 24 & 141 & 3919 & 0.691 & 1500 & 2.30 & 3913 \\
\hline 23 & 135 & 3751 & 0.688 & 1500 & 2.20 & 3899 \\
\hline 22 & 129 & 3583 & 0.686 & 1500 & 2.10 & 3887 \\
\hline 21 & 123 & 3415 & 0.683 & 1500 & 2.00 & 3872 \\
\hline 20 & 117 & 3247 & 0.683 & 1500 & 1.90 & 3876 \\
\hline 19 & 108 & 3009 & 0.678 & 1500 & 1.76 & 3842 \\
\hline 18 & 104 & 2832 & 0.671 & 1400 & 1.76 & 3710 \\
\hline 17 & 101 & 2655 & 0.664 & 1300 & 1.76 & 3573 \\
\hline 16 & 96.4 & 2478 & 0.656 & 1200 & 1.76 & 3431 \\
\hline 15 & 91.4 & 2298 & 0.627 & 1100 & 1.74 & 3205 \\
\hline 14 & 86.7 & 2177 & 0.630 & 1100 & 1.65 & 3220 \\
\hline 13 & 82.4 & 2059 & 0.639 & 1100 & 1.57 & 3247 \\
\hline 12 & 77.7 & 1939 & 0.636 & 1100 & 1.48 & 3228 \\
\hline 11 & 72.5 & 1818 & 0.631 & 1100 & 1.38 & 3218 \\
\hline 10 & 67.7 & 1697 & 0.632 & 1100 & 1.29 & 3221 \\
\hline 9 & 62.6 & 1578 & 0.620 & 1100 & 1.19 & 3183 \\
\hline 8 & 57.3 & 1457 & 0.613 & 1100 & 1.09 & 3175 \\
\hline 7 & 52.0 & 1330 & 0.607 & 1100 & 0.99 & 3156 \\
\hline 6 & 46.8 & 1209 & 0.598 & 1100 & 0.89 & 3144 \\
\hline 5 & 41.5 & 1089 & 0.584 & 1100 & 0.79 & 3119 \\
\hline 4 & 36.3 & 969 & 0.568 & 1100 & 0.69 & 3086 \\
\hline 3 & 31.1 & 846 & 0.546 & 1100 & 0.59 & 3027 \\
\hline 2 & 26.9 & 724 & 0.537 & 1100 & 0.51 & 2942 \\
\hline 1 & 23.6 & 603 & 0.493 & 850 & 0.51 & 2566 \\
\hline 0 & 20.2 & 483 & 0.445 & 650 & 0.50 & 2163 \\
\hline & & & & & & \\
\hline
\end{tabular}

were obtained from the National Institute of Standards and Technology (NIST) Physical Reference Data. ${ }^{29}$ Energy levels and some relative intensities were obtained from Striganov and Sventitskii. ${ }^{30}$

\section{EMISSION SPECTROSCOPY RESULTS}

The primary goal of the spectroscopic investigation was to determine the prevalence of erosion product spectra in the emissions from a thruster under various operating conditions. While the emission in the beam proved too weak to be observed using the fiber optic scheme mentioned previously, the spectra in the discharge chamber contained a number of lines as shown in Figure 5. The spectra has been separated in 100-nm sections in
Figure 5 for clarity in the designation of the peaks. Throttle condition 15 is shown in Figure 5 because it is the NSTAR maximum power condition and therefore provides a reference point to a thoroughly evaluated operating point. The results of the 8192-hour wear-test showed a slight chamfering of the upstream face of the molybdenum screen grid apertures, resulting in an estimated mass loss of $0.23-$ g. $^{2}$ The emission spectrum is comprised mostly of singly ionized xenon lines, with a lesser degree of neutral xenon and low-level atomic titanium and nitrogen (background gas) emissions. The lines shown in Figure 5 are representative of those seen at each of the other throttle conditions.

Several of the neutral titanium lines were examined to determine the scaling of their intensity with the beam current, and the results are presented in Figure 6. The line strength increased with current. Since the line intensity is, in general, a function of 


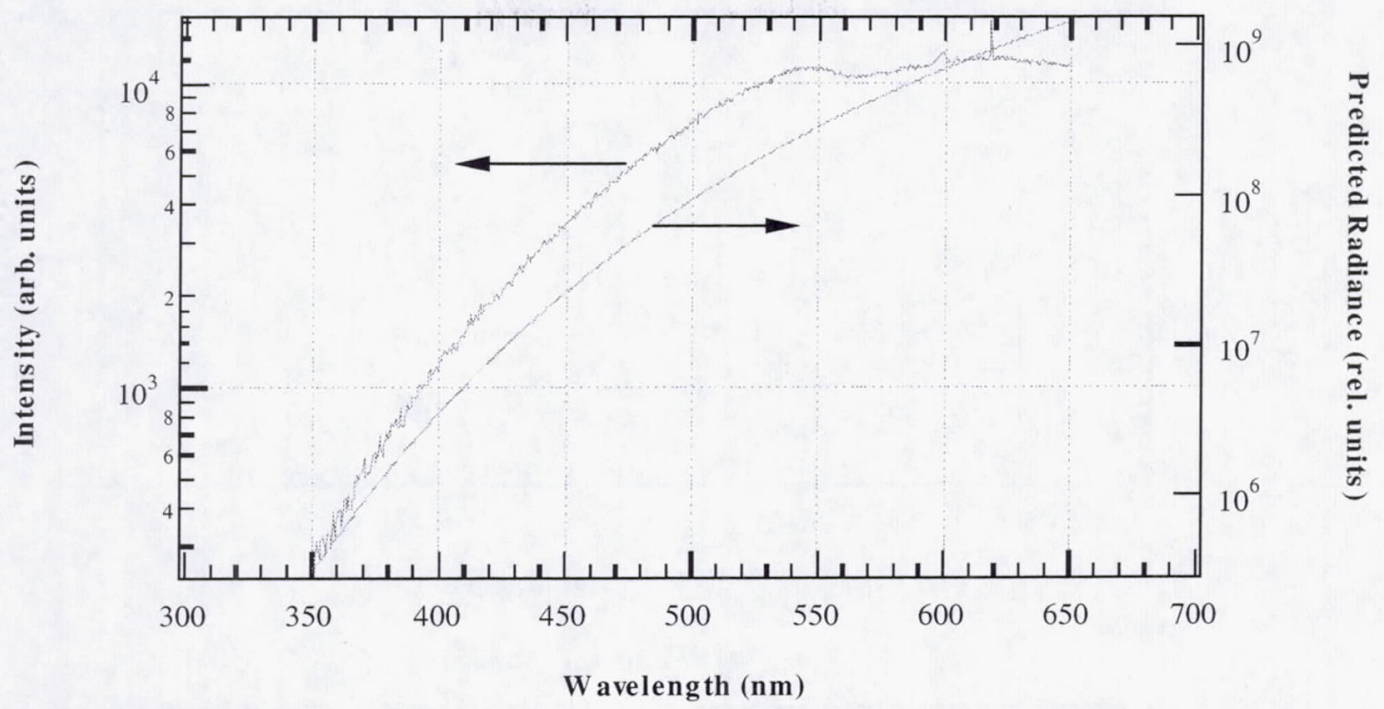

Figure 3 - Magnitude Calibration of the Fiber-Optic/Spectrometer System with a Tungsten Filament Lamp

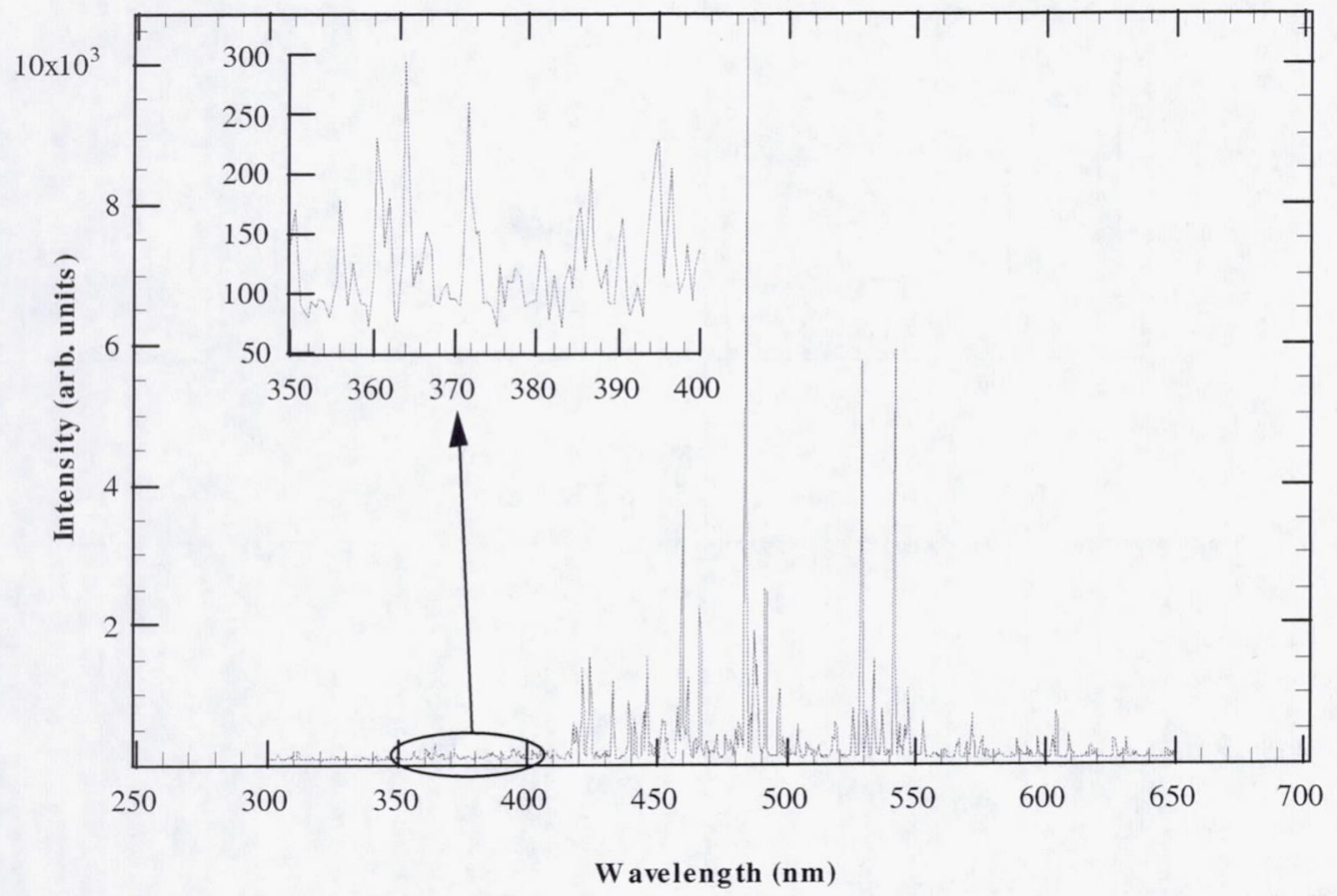

Figure 4 - Sample Discharge Chamber Spectra Obtained from the Internal Fiber Optic Probe. (TH28) 


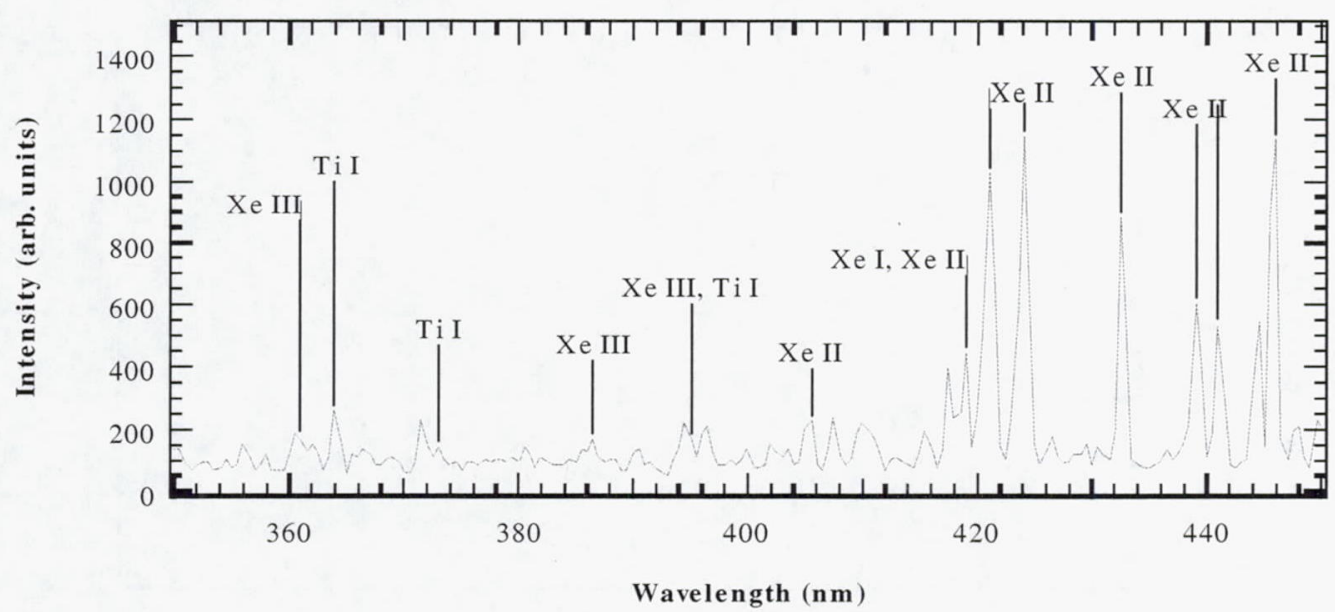

a) 350 to $450-\mathrm{nm}$

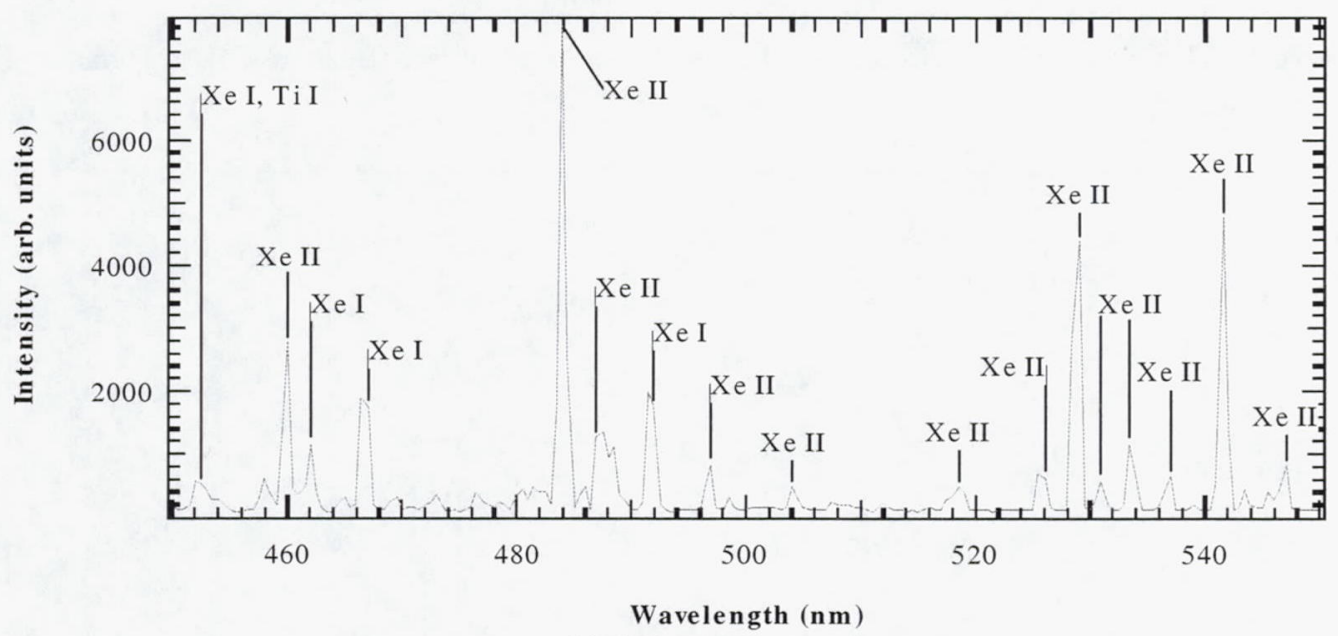

b) 450 to $550-\mathrm{nm}$

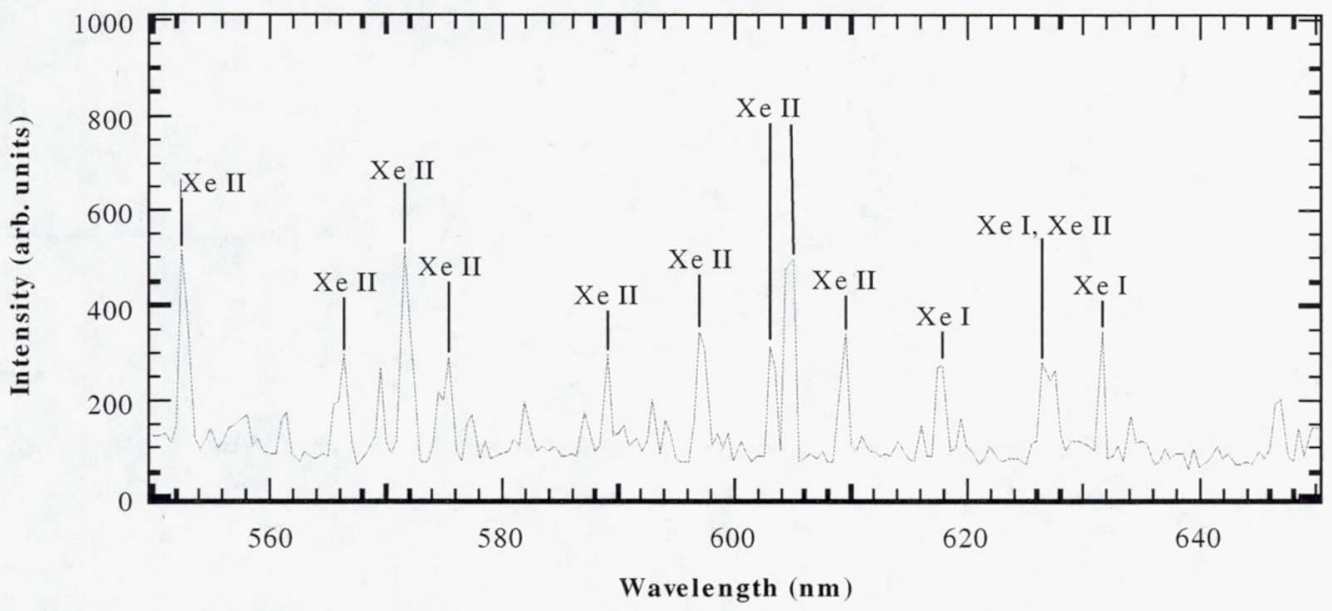

c) 550 to $650-\mathrm{nm}$

Figure 5 - Detailed Spectra at TH15 with Line Identification. 


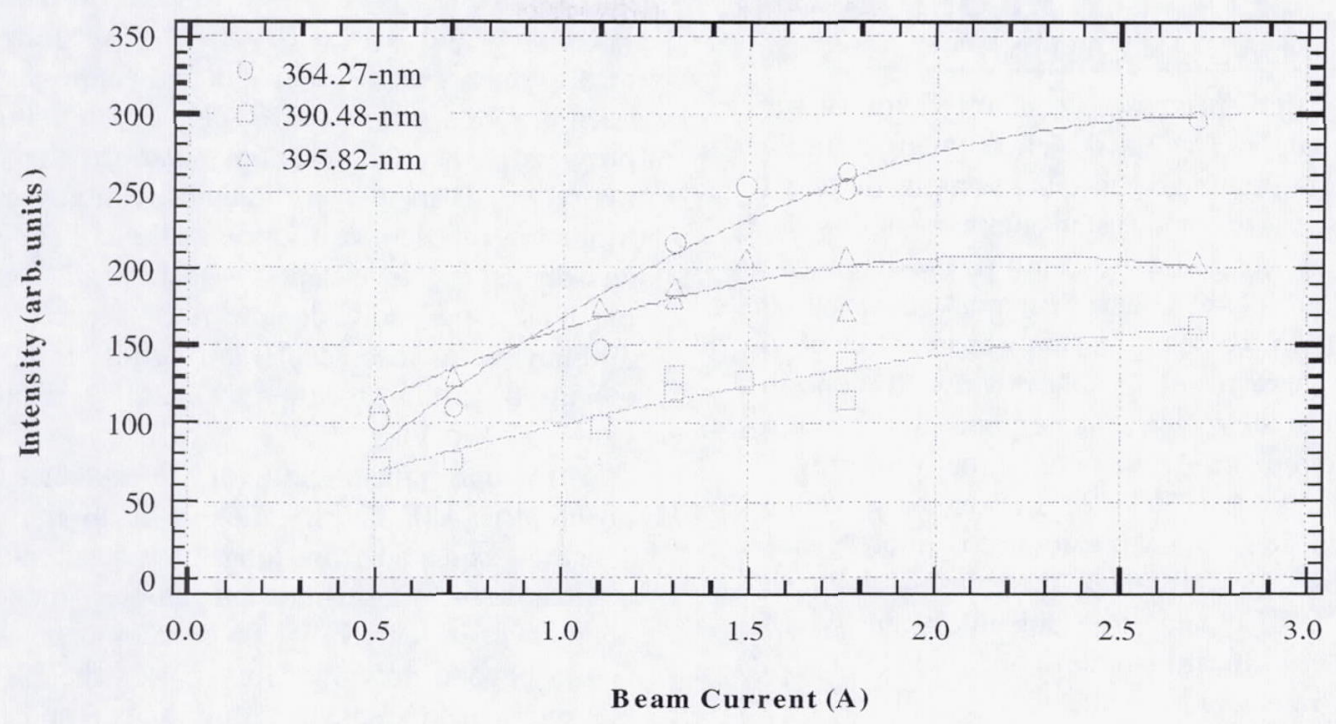

Figure 6 - Variation of the Relative Intensities of Several Titanium Lines in the Discharge Chamber as a Function of Beam Current

atom density, electron density, and electron energy distribution function for a collisionally excited population, trends in titanium density cannot be discerned from the data in Figure 6 without additional information on the electron population in the discharge chamber. The technique by Rock, Mantenieks, and Parsons ${ }^{23}$ can be applied to the titanium atom population in the discharge, however the accuracy of the density estimate is limited by the few transitions observed. To bolster the effectiveness of this technique with a titanium screen grid, additional titanium lines must be detected. The scatter in the intensity of the titanium lines with the beam current emphasizes the necessity for additional transitions to give the technique a better statistical foundation.

\section{ANALYSIS AND DISCUSSION OF EMISSION SPECTROSCOPY FOR EROSION MEASUREMENTS}

The geometry of the ion thruster precludes examination of the discharge chamber environment without significant modifications; in order to perform LIF measurements in the discharge chamber, Williams et $\mathrm{al}^{8}{ }^{8}$ used three windows mounted to the conical section of an NSTAR derivative thruster. The use of a fiber optic probe mounted to the discharge chamber was non-intrusive and required only a minor modification to the discharge chamber. However, the plasma induced fluorescence of the erosion products yielded relatively weak signals. The minimal level of erosion product lines in the emission spectra is the result of both a low erosion-rate and the limited amount of light collected by the $200-\mu \mathrm{m}$ diameter fiber optic. Since the maximum discharge voltage in these experiments was $26.2-\mathrm{V}$, few doubly charged ions were expected to be created, and the erosion-rate was expected to be low. The value of $18-\mathrm{eV}$ for the sputtering threshold of titanium by xenon was used despite the contentious nature of these measurements. ${ }^{31,32}$ Depending on the size of the anode fall voltage, ions in the discharge chamber had sufficient energy to sputter the titanium screen grid. Qualitatively, the discharge chamber emission spectra support these suppositions.

In an attempt to enhance the signal of the erosion products in the discharge chamber, the screen grid was biased 10 and $20-\mathrm{V}$ below cathode to increase the ion impingement energy. The results however were inconclusive. While perturbing the discharge in order to test the detection limits of the emission spectroscopy diagnostic is useful in the preliminary stages of development, the goal is to develop a passive erosion-rate measurement technique. In order to determine the erosion-rate inside the discharge chamber from the emission spectra, improved collection optics must be employed. This is the domain of future research. The goal will be accomplished either with miniature collection optics for the fiber optic probe or by using direct viewing of the discharge chamber through the grids. The latter method, as performed by Rock, Mantenieks, and Parsons ${ }^{23}$ with a mercury ion thruster, appears to be reasonable based on the weak emission from the beam plasma. 


\section{QUANTITATIVE EROSION MEASUREMENTS}

Although the spectroscopic investigation of the discharge chamber yielded encouraging initial results, the accelerator grid lifetime remains the most immediate life issue for thruster engineers and is the focus of an ongoing erosion-rate diagnostic development project at Glenn Research Center. The weak emission in the beam plasma was insufficient to decipher the character of the plasma, not to mention the erosion products. In this region, interrogation must be accomplished with either greatly improved collection optics or LIF. For LIF to be a viable erosion diagnostic, the laser-induced fluorescence must be much greater than the plasma induced fluorescence (PIF) and the absolute density of sputtered material must be determined. Gaeta et $_{\text {al. }}{ }^{24}$ developed a ratio for the intensity of LIF to PIF. Since the rate of radiative excitation is proportional to the laser intensity in an optically thin plasma, the laser power determines the signal-to-noise ratio. Based upon the formula reported by Gaeta et al., ${ }^{25}$ the theoretical ratio is on the order of $10^{7}$ for a 100 $\mathrm{mW}$ beam focused to a $1-\mathrm{mm}^{2}$ spot for the $390.2-\mathrm{nm}$ transition of molybdenum. While this estimate is encouraging, the absolute fluorescence must still be sufficiently large to detect accurately. Brinza et al. ${ }^{19}$ calculated the molybdenum number density in the vicinity of the accelerator grid to be $6.6 \times 10^{6}-\mathrm{cm}^{-3}$. The maximum molybdenum number density downstream of the grids was estimated here as

$$
\text { Eqn. } 1 \quad \mathrm{n}_{\mathrm{Mo}, \max } \approx \frac{\mathrm{m}_{\mathrm{L}}}{\mathrm{MtA} \bar{v}_{\mathrm{e}}} \mathrm{F}_{\mathrm{b}} \mathrm{f}_{\mathrm{d}}
$$

where $m_{L}$ is the mass loss in $\mathrm{kg}$ over a period of time $\mathrm{t}, \mathrm{M}$ is the atomic mass in $\mathrm{kg}, \mathrm{A}$ is the entire grid area, $\overline{\mathrm{V}}_{\mathrm{e}}$ is the average velocity of the sputtered material, $F_{b}$ is the correction factor for the radial distribution of ion current, and $f_{d}$ is the fraction of sputtered material which is ejected with velocity components in the downstream direction. The average velocity of the sputtered atoms was estimated to be between $4 \times 10^{3}$ and $1 \times 10^{4}$-m/s based on the data of Stuart, Wehner, and Anderson. ${ }^{33}$ This brackets a wide range, but molybdenum is expected to be closer to the lower limit due to its atomic mass. The radial distribution of ion current was varied from 1 (uniform) to 1.3 (slightly peaked on axis), and 50 to 100 percent of the ejected material was assumed to flow downstream. Using the mass loss of $10.81 \mathrm{~g}$ in the NSTAR 8192-hour test, the number density near the accelerator grid was estimated to be between $1.5 \times 10^{6}$ and $1.1 \times 10^{7}-\mathrm{cm}^{-3} \cdot{ }^{2}$ Accurate density measurements using laser-induced fluorescence have been reported as low as $10^{8}-\mathrm{cm}^{-3} .^{27,34}$ Orsitto et al. ${ }^{27}$ provided a detailed sensitivity and error analysis for the reported LIF density diagnostic, and the primary limitation on the sensitivity was the collection optics and detector. Nevertheless, Gaeta et $a .^{25}$ were able to detect the molybdenum fluorescence signal at $390-\mathrm{nm}$ with the accelerator grid at $-200-\mathrm{V}$, a condition similar to the NSTAR beginning-of-life value of $-180-\mathrm{V}$.

Despite the lack of precedence for a quantitative LIF density diagnostic in the range of densities expected from long-lived accelerator grids, a quantitative laser-induced fluorescence density diagnostic is currently in development at GRC. Going beyond previous works, ${ }^{24,25,26}$ the LIF density measurements include a calibration cell and computer modeling to relate the density distribution to an erosion-rate and lifetime of the grid. Figure 7 summarizes the execution of the diagnostic. The following paragraphs discuss the diagnostic in detail.

\section{Laser-induced Fluorescence}

The laser-induced fluorescence erosion material density diagnostic currently being developed at GRC will initially incorporate a small interrogation region determined by the focusing optics. The laser system currently consists of a pulsed Nd:YAG laser which is used to pump a dye laser. The diagnostic will be evaluated with molybdenum grids due to the heritage of this grid material with NSTAR and the previous LIF erosion measurement works. ${ }^{2,25,26}$ Orsitto et al. ${ }^{27}$ pumped the $\mathrm{a}^{7} \mathrm{~S}_{3}-\mathrm{z}^{5} \mathrm{P}_{3}^{0}$ transition at 345.64-nm which fluoresces primarily at 550.6-nm $\left(z^{5} \mathrm{P}_{3}^{0}--\mathrm{a}^{5} \mathrm{~S}_{2}\right)$. This method is advantageous because the detector will be unaffected by scattering from the laser, and the fluorescence is more than 1-nm from the nearest xenon (I, II, or III) line. Ultimately, the LIF diagnostic will also be used to evaluate the lifetimes of both titanium and carbon-carbon composite grids. Titanium has several ultraviolet transitions which may be useful for the LIF erosion diagnostic. ${ }^{28} \mathrm{~A}$ cursory examination of the spectra of carbon indicated that the most attractive lines for LIF were also within the ultraviolet. To generate beams at these wavelengths, the output of the pulsed dye laser will be frequency doubled. In most cases, the fluorescence is also in the ultraviolet, and an intensified CCD (ICCD) array with photon-counting capability will be used to collect the signal. 


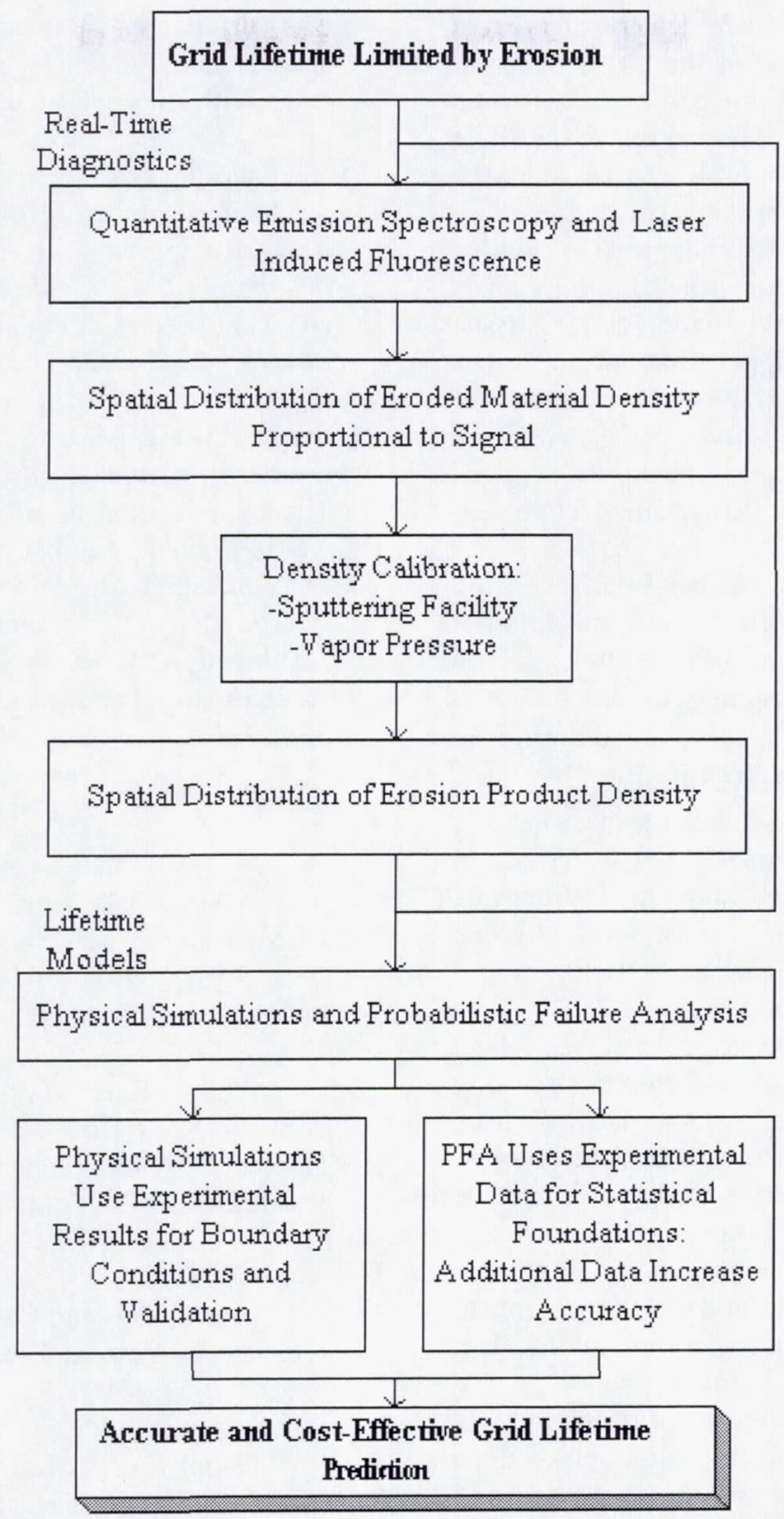

Figure 7 - Approach to Develop Accurate and Cost-Effective Grid Lifetime Diagnostics.

\section{Calibration}

Two calibration techniques for the LIF erosion material density measurement apparatus are currently under examination at GRC. The premise of both techniques is to produce a known density of erosion product neutrals which can be measured using the collection optics that will be used with the thruster. One method uses a high flux sputtering source to erode the target material. The erosion will be measured using a highly accurate balance, a mass loss technique. This method is advantageous because the environment is similar to the beam of the thruster.
The density of eroded neutrals must be calculated using a model for their emission, and this is a source of uncertainty in this calibration technique.

An alternate calibration method employs knowledge of the vapor pressure of the target species at elevated temperatures (1600 to $1900-\mathrm{K})$. Assuming the vaporized atoms are emitted in thermal equilibrium with a surrounding container of the same material, the number density near the surface is calculated using the ideal gas law. Laser induced fluorescence signals collected from this standard are corrected for thermal effects to yield an absolute 
calibration based on the number density of erosion products. Using a small tube of the target material, the internal density and pressure are expected to be relatively uniform near the midpoint if the tube temperature distribution is uniform. In practice, the tube will exhibit some variation in temperature axially if it is supported at its endpoints. Provided the axial temperature variation near the midpoint is small, the non-uniformity can be ignored. This issue is currently under investigation. Although the vapor pressure method is advantageous in terms of simplicity and the accuracy to which the density of the target species is known, care must be exercised either in the design of the fluorescence collection scheme to minimize the amount of graybody radiation viewed from the container or in choosing the fluorescence transition such that it is much larger than the graybody radiation of the tube. The calibration methods are undergoing evaluation.

\section{Modeling the Results to Predict Lifetime}

Since the LIF diagnostic yields a measurement of the density of the eroded material near the grid, a model must be developed to calculate the erosion-rate and grid lifetime from the LIF results. Both physical models and probabilistic failure analysis have been used to predict grid erosion and lifetime..$^{21,35,36,37}$ The strength of physical models has always been that, following a successful validation, different operating conditions can be simulated with relatively little additional time or cost. The drawback of the physical models has been the difficulty in validation and the associated uncertainties in predicting untested geometries or conditions. Particle simulation techniques employed to study grid erosion appear to be the best candidate for incorporation of the LIF density data to yield a grid lifetime model. The ability of a probabilistic failure model to incorporate new data as it is generated to refine predictions argues for the use of this technique. The scope and details of the modeling for the LIF density diagnostic are the subject of future work.

\section{SUMMARY}

The attributes of erosion measurement techniques were assessed as a preliminary step to developing real-time erosion diagnostics for ion thruster grids. Optical emission spectra were collected from within the discharge chamber and immediately downstream of the NSTAR derivative titanium grids using fiber optics. The plasma induced fluorescence in the discharge chamber was sufficient to excite the titanium present, however collisional processes in the beam plasma were below the limit of detection with the optics used in this investigation.
The discharge chamber spectra were useful for species identification.

With improved collection, the model presented by Rock, Mantenieks, and Parsons ${ }^{23}$ may prove adequate to describe erosion processes within the discharge chamber. This model uses the excitation state of a species with much greater density to infer the distribution of the erosion species. Using the emission spectra to determine the erosion-rate results in a very passive measurement.

Based on a literature review, laser-induced fluorescence appears to be the best option for a realtime erosion-rate diagnostic for the accelerator grid. The experimental approach being executed at GRC was presented. The LIF portion of the diagnostic will be conducted in a manner similar to previous efforts. $^{25,26}$ In addition, the diagnostic being developed at GRC will include calibration and modeling to relate the density measurement to the life of the grid.

\section{REFERENCES}

${ }^{1}$ Sovey, J.S., et al., "Development of an Ion Thruster and Power Processor for New Millennium's Deep Space 1 Mission," AIAA Paper No. 97-2778, $33^{\text {rd }}$ Joint Propulsion Conference, Seattle, WA, 1997.

${ }^{2}$ Polk, J.E., et al., "An Overview of the Results from the 8200 Hour Wear Test of the NSTAR Ion Thruster," AIAA Paper No. 99-446, 35 th AIAA/ ASME/SAE/ASEE Joint Propulsion Conference and Exhibit, Los Angeles, CA, June 1999.

${ }^{3}$ Bond, T.A. and Christensen, J.A., "NSTAR Ion Thrusters and Power Processors," NASA/CR-1999209162, Nov. 1999.

${ }^{4}$ Brophy, J., "Ion Propulsion-A Legitimate Option for Deep-Space Missions," Eleventh Annual NASA/JPLMSFC Advanced Propulsion Research Workshop, Pasadena, CA, May-June 2000.

${ }^{5}$ Patterson, M.J., Domonkos, M.T., Foster, J.E., Haag, T.W., Mantenieks, M.A., Pinero, L., Rawlin, V.K., Sarver-Verhey, T.R., Soulas, G.C., Sovey, J.S., and Strzempkowski, E., "Ion Propulsion Development Activities at NASA Glenn Research Center," AIAA Paper No. 2000-3810, 36 $6^{\text {th }}$ AIAA/ ASME/SAE/ASEE Joint Propulsion Conference and Exhibit, Huntsville, AL, July 2000.

${ }^{6}$ Patterson, M.J., Roman, R.F., and Foster, J.E., "Ion Engine Development for Interstellar Precursor Missions," AIAA Paper No. 2000-3811, $36^{\text {th }}$ 
AIAA/ASME/SAE/ASEE Joint Propulsion Conference and Exhibit, Huntsville, AL, July 2000.

${ }^{7}$ Patterson, M.J., et al., "2.3 kW Ion Thruster Wear Test," AIAA Paper No. 95-2516, 31 ${ }^{\text {st }}$ AIAA/ ASME/SAE/ASEE Joint Propulsion Conference, San Diego, CA, July 1995.

${ }^{8}$ Williams, G.J., Smith, T.B., Patrick, T.A., and Gallimore, A.D., "Characterization of the FMT-2 Discharge Cathode Plume," IEPC Paper No. 99-104, $26^{\text {th }}$ International Electric Propulsion Conference, Kitakyushu, Japan, Oct. 1999.

${ }^{9}$ Kameyama, I. and P.J. Wilbur, "Zenith-Angle Distributions of Erosion-rates near High-Current Hollow Cathodes," AIAA Paper No. 96-3208, 32 $2^{\text {nd }}$ AIAA/ASME/SAE/ASEE Joint Propulsion Conference, Lake Buena Vista, FL, July 1996.

${ }^{10}$ Kerslake, W.R., "Charge-Exchange Effects on the Accelerator Impingement of an ElectronBombardment Ion Rocket," NASA TN D-1657, May 1963.

${ }^{11}$ Rawlin, V.K., "Characterization of Ion Thruster Accelerating Systems on NASA LeRC's Ion Thrusters," AIAA Paper No. 92-3827, AIAA/ ASME/SAE/ASEE $28^{\text {th }}$ Joint Propulsion Conference and Exhibit, Nashville, TN, July 1992.

${ }^{12}$ Shimada, S., et al., "Ion Thruster Endurance Test Using Development Model Thruster for ETSVI," IEPC Paper No. 93-169, AIAA/AIDAA/ DGLR/JSASS $23^{\text {rd }}$ International Electric Propulsion Conference, Seattle, WA, Sept. 1993.

${ }^{13}$ Rawlin, V.K., "Erosion Characteristics of Two-Grid Ion Accelerating Systems," IEPC Paper No. 93-175, AIAA/AIDAA/DGLR/JSASS $23^{\text {rd }}$ International Electric Propulsion Conference, Seattle, WA, Sept. 1993.

${ }^{14}$ Brophy, J.R., Polk, J.E., Pless, L.C., "Test-toFailure of a Two-Grid, 30-cm-dia. Ion Accelerator System," IEPC Paper No. 93-172, AIAA/AIDAA/ DGLR/JSASS $23^{\text {rd }}$ International Electric Propulsion Conference, Seattle, WA, Sept. 1993.

${ }^{15}$ Fearn, D.G., "Ion Thruster Lifetime Limitations Imposed by Sputtering Processes," IEPC Paper No. 93-177, AIAA/AIDAA/DGLR/JSASS $23^{\text {rd }}$ International Electric Propulsion Conference, Seattle, WA, Sept. 1993.
${ }^{16}$ Beattie, J.R., "A Model for Predicting the Wearout Lifetime of the LeRC/Hughes 30-cm Mercury Ion Thruster," AIAA Paper No. 79-2079, Princeton/AIAA/DGLR $14^{\text {th }}$ International Electric Propulsion Conference, Princeton, NJ, Oct.-Nov. 1979.

${ }^{17}$ Poeschel, R.L., and Beattie, J.R., "Primary Electric Propulsion Technology Study," Final Report, Contract NAS 3-21040, Nov. 1970.

${ }^{18}$ Hurst, E.B. and Thomas, G.Z., "Diagnostic System Design for the Ion Auxiliary Propulsion System (IAPS)--Flight Test of Two $8 \mathrm{~cm}$ Mercury Ion Thrusters," NASA TM-81702, also AIAA Paper No. 81-0666, AIAA/JSASS/DGLR $15^{\text {th }}$ International Electric Propulsion Conference, Las Vegas, NV, Apr. 1981.

${ }^{19}$ Brinza, D., Wang, J., Polk, J., and Henry, M., "Deep Space One Investigations of Ion Propulsion Contamination: Overview and Initial Results," AIAA Paper No. 2000-0465, 38 ${ }^{\text {th }}$ Aerospace Sciences Meeting and Exhibit, Reno, NV, 2000.

${ }^{20}$ Polk, J.E., et al., "The Effect of Engine Wear on Performance in the NSTAR 8000 Hour Ion Engine Endurance Test," AIAA Paper No. 97-3387,

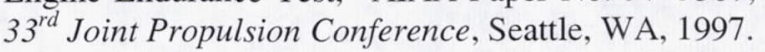

${ }^{21}$ Tartz, M., Hartmann, E., Deltschew, R., and Neumann, H., "Validation of a Grid Erosion Simulation by Short-Time Erosion Measurements," IEPC Paper No. 99-147, $26^{\text {th }}$ International Electric Propulsion Conference, Kitakyushu, Japan, Oct. 1999.

${ }^{22}$ Polk, J.E., et al., "In Situ, Time-Resolved Accelerator Grid Erosion Measurements in the NSTAR 8000 Hour Ion Engine Wear Test," IEPC Paper 97-047, 25 International Electric Propulsion Conference, Cleveland, OH, Aug. 1997.

${ }^{23}$ Rock, B.A., Mantenieks, M.A., and Parsons, M.L., "Rapid Evaluation of Ion Thruster Lifetime Using Optical Emission Spectroscopy," AIAA/DGLR/JSASS $18^{\text {th }}$ International Electric Propulsion Conference, Alexandria, VA, Sept.-Oct. 1985.

${ }^{24}$ Gaeta, C.J., et al., "Plasma Erosion-rate Diagnostics Using Laser-Induced Fluorescence," Review of Scientific Instruments, Vol. 63, No. 5, May 1992, pp. 3090-3095. 
${ }^{25}$ Gaeta, C.J., Matossian, J.N., Turley, R.S., Beattie, J.R., Williams, J.D., and Williamson, W.S., "Erosion-rate Diagnostics in Ion Thrusters Using Laser-induced Fluorescence," Journal of Propulsion and Power, Vol. 9, No. 3, May-June 1993, pp. 369376.

${ }^{26}$ Crofton, M.W., "Laser Spectroscopic Study of the T5 Ion Thruster," AIAA Paper 95-2921, $31^{\text {st }}$ AIAA/ASME/SAE/ASEE Joint Propulsion Conference, San Diego, CA, July 1995.

${ }^{27}$ Orsitto, F., et al., "MoI Density Measurements by Laser-induced Fluorescence Spectroscopy," Review of Scientific Instruments, Vol. 70, No. 1, Jan. 1999, pp. 921-924.

${ }^{28}$ Ljung, P., et al., "Detection of Titanium in Electrothermal Atomizers by Laser-induced Fluorescence. Part 1. Determination of Optimum Excitation and Detection Wavelengths," Spectrochimica Acta, Part B, Vol. 52, 1997, pp. 675701.

$\begin{array}{cccc}{ }^{29} \text { National } & \text { Institute of Standards and } \\ \text { Technology, } & \text { Physical } & \text { Reference } & \text { Data, }\end{array}$
http://physics.nist.gov/PhysRefData/contentsatomic.html

${ }^{30}$ Striganov, A.R. and Sventitskii, N.S., Tables of Spectral Lines of Neutral and Ionized Atoms, IFI/Plenum Data Corporation, New York, NY, 1968.

${ }^{31}$ Stuart, R.V. and Wehner, G.K., "Sputtering at Very Low Bombarding Energies," Journal of Applied Physics, Vol. 33, No. 7, 1962, pp. 2345-2352.

${ }^{32}$ Mantenieks, M.A., "Sputtering Threshold Energies of Heavy Ions," NASA/TM-1999-209273, June 1999.

${ }^{33}$ Stuart, R.V., Wehner, G.K., and Anderson, G.S., "Energy Distributions of Atoms Sputtered from Polycrystalline Metals," Journal of Applied Physics, Vol. 40, No. 2, Feb. 1969, pp. 803-812.

${ }^{34}$ Hershkowitz, N. and Breun, R.A., "Diagnostics for Plasma Processing (Etching Plasmas)," Review of Scientific Instruments, Vol. 68, No. 1, Jan. 1997, pp. 880-885.

${ }^{35}$ Nakano, M. and Arakawa, Y., "Ion Thruster Lifetime Estimation and Modeling Using Computer Simulation," IEPC Paper No. 99-145, $26^{\text {th }}$
International Electric Propulsion Conference, Kitakyushu, Japan, Oct. 1999.

${ }^{36}$ Peng, X., Ruyten, W.M., and Keefer, D., "Charge-Exchange Grid Erosion Study for GroundBased and Space-Based Operations of Ion Thrusters," IEPC Paper No. 93-173, AIAA/AIDAA/DGLR/JSASS $23^{\text {rd }}$ International Electric Propulsion Conference, Seattle, WA, Sept. 1993.

${ }^{37}$ Polk, J.E., et al., "Probabilistic Analysis of Ion Engine Accelerator Grid Life," IEPC Paper No. 93176, AIAA/AIDAA/DGLR/JSASS $23^{\text {rd }}$ International Electric Propulsion Conference, Seattle, WA, Sept. 1993. 
Davis Highway, Suite 1204, Arlington, VA 22202-4302, and to the Office of Management and Budget, Paperwork Reduction Project (0704-0188), Washington, DC 20503.

\begin{tabular}{|l|l|r|}
\hline 1. AGENCY USE ONLY (Leave blank) & $\begin{array}{r}\text { 2. REPORT DATE } \\
\text { September } 2000\end{array}$ & $\begin{array}{r}\text { 3. REPORT TYPE AND DATES COVERED } \\
\text { Technical Memorandum }\end{array}$ \\
\hline
\end{tabular}

4. TITLE AND SUBTITLE

Assessment of Spectroscopic, Real-Time Ion Thruster Grid

Erosion-Rate Measurements

6. $\operatorname{AUTHOR}(\mathrm{S})$

Matthew T. Domonkos and Richard E. Stevens

\section{PERFORMING ORGANIZATION NAME(S) AND ADDRESS(ES)}

National Aeronautics and Space Administration John H. Glenn Research Center at Lewis Field Cleveland, Ohio 44135-3191

9. SPONSORING/MONITORING AGENCY NAME(S) AND ADDRESS(ES)

National Aeronautics and Space Administration

Washington, DC 20546-0001
5. FUNDING NUMBERS

WU-632-6B-1C-00

8. PERFORMING ORGANIZATION REPORT NUMBER

E-12455

10. SPONSORING/MONITORING AGENCY REPORT NUMBER

NASA TM-2000-210459

AIAA-2000-3815

\section{SUPPLEMENTARY NOTES}

Prepared for the 36th Joint Propulsion Conference and Exhibit cosponsored by the AIAA, ASME, SAE, ASEE, Huntsville, Alabama, July 16-19, 2000. Matthew T. Domonkos, NASA Glenn Research Center; and Richard E. Stevens Whitworth College, Spokane, Washington 99251. Responsible person, Matthew T. Domonkos, organization code 6920 , (216) 433-2164.

12a. DISTRIBUTION/AVAILABILITY STATEMENT 12b. DISTRIBUTION CODE

Unclassified - Unlimited

Subject Category: 20

Distribution: Nonstandard

This publication is available from the NASA Center for AeroSpace Information, (301) 621-0390.

13. ABSTRACT (Maximum 200 words)

The success of the ion thruster on the Deep Space One mission has opened the gate to the use of primary ion propulsion. Many of the projected planetary missions require throughput and specific impulse beyond those qualified to date. Spectroscopic, real-time ion thruster grid erosion-rate measurements are currently in development at the NASA Glenn Research Center. A preliminary investigation of the emission spectra from an NSTAR derivative thruster with titanium grid was conducted. Some titanium lines were observed in the discharge chamber; however, the signals were too weak to estimate the erosion of the screen grid. Nevertheless, this technique appears to be the only non-intrusive real-time means to evaluate screen grid erosion, and improvement of the collection optics is proposed. Direct examination of the erosion species using laser-induced fluorescence (LIF) was determined to be the best method for a real-time accelerator grid erosion diagnostic. An approach for a quantitative LIF diagnostic was presented.

\section{SUBJECT TERMS}

\begin{tabular}{|c|c|}
\hline & 15. NUMBER OF PAGES \\
\hline & 20 \\
\hline & 16. PRICE CODE \\
\hline & $\mathrm{A} 03$ \\
\hline $\begin{array}{l}\text { 19. SECURITY CLASSIFICATION } \\
\text { OF ABSTRACT }\end{array}$ & 20. LIMITATION OF ABSTRACT \\
\hline Unclassified & \\
\hline
\end{tabular}

Ion thruster; Erosion; Spectroscopy

\begin{tabular}{|c|c|}
\hline $\begin{array}{l}\text { 17. SECURITY CLASSIFICATION } \\
\text { OF REPORT }\end{array}$ & $\begin{array}{c}\text { 18. SECURITY CLASSIFICATION } \\
\text { OF THIS PAGE } \\
\text { Unclassified }\end{array}$ \\
\begin{tabular}{c} 
Unclassified \\
\hline
\end{tabular}
\end{tabular}

